\title{
BIODIESELS AS A FUNCTION OF ENVIRONMENTAL PROTECTION
}

\section{Lovro Babić, mag.ing.agr. Vocational School Vukovar, 32000 Vukovar, Croatia, email: lovrobabic@gmail.com}

\section{Ivan Gregić, dipl.ing. Agriculture Faculty, 31000 Osijek, Croatia}

\begin{abstract}
Abstarct: As of July 1st 2013. the Republic of Croatia will be a member of the European Union, which will primarily bring necessary harmonisation of ecological standards and requirements. Biodiesel, as a renewable source of energy, can be produced from algae, vegetable oil, and animal fats, and thus it is biodegradable. Biodiesel in Croatia is mainly produced from oilseed rape which, as an agricultural plant, has an increasing share in the past three years and records positive trends. This paper analyses the trend of production in the Republic of Croatia, and compares it with the production and consumption of fossil fuels. On the grounds of Croatia's favourable agriculture-related climatic characteristics, in particular in the region of Slavonija and Baranja, more intense exploitation of farm land under the cultures intended for biodiesel production can be organised aiming at bumper yield and production. Croatia has already harmonised its standards of production of biodiesel, and by 2020 the consumption of biodiesel is bound to reach $20 \%$.

The data used in this paper are obtained from the sources available by Croatian Institute of Statistics, Market Information System in Agriculture, as well as Eurostat, and the rest used here are translated from the sources in the English language. The reviewed are the surfaces planted with oilseed rape in the period between 2007. and 2011., an average yield, and overall production. On the grounds of available information, the calculations of the quantity of bio fuel to be consumed in Croatia by 2020. and the percentage of the land surfaces planted with oilseed rape have been made.
\end{abstract}

environment

Key words: biodiesel, production,

\section{INTRODUCTION}

Biodiesel is a renewable and biodegradable fuel produced from vegetable oil, animal fats, and recycled waste cooking oils by means of chemical modification. In Europe, biodiesel is mainly produced from oilseed rape. The idea of using vegetable oil as a power of internal-combustion engines is very old and associated with the inventor of a diesel engine - Rudolf Diesel. In 1900, he showed it at the world exhibition in Paris, and demonstrated the operation of a diesel engine powered by peanut oil. However, due to a low price of crude oil at that time, the idea was abandoned.

The most important characteristics of biodiesel are related with low environment pollution. When an engine runs, even up to $10 \%$ of oxygen comes out through the exhaust pipe. Biodiesel fuels contain neither sulphur nor heavy metals which are the main substances that pollute air when a diesel fuel produced from crude oil is used. The most advantageous characteristic of biodiesel is reduced emission of glass-house gases which is similar in the amount absorbed by a plant throughout its growth.

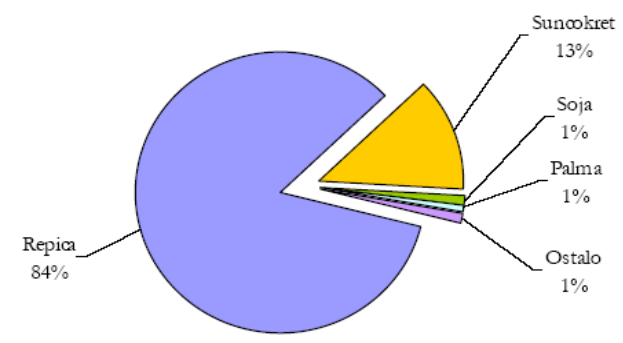

Chart 1: Share of various agricultural cultures in biodiesel production 
Source: World-wide Trends in Production and Marketing of Biodiesel, Werner Körbitz, Austrian Bio fuels Institute

Ten years ago in the Republic of Croatia, the Government has initiated the start of biodiesel production from a number of factors, which are accompanied by many goals. The main objectives are to reduce the import of fossil fuels and dependence on changing their prices, and immersing the "third" culture in addition to agricultural crops of wheat and corn, and safe market for farmers.

\section{PRODUCTION OF BIODIESEL IN CROATIA}

Current capacity for biodiesel production in Croatia are 61,000 tons of biodiesel annually. Planned total capacity for processing the oil into biodiesel is far greater than the existing ones, or 391,000 tons of biodiesel annually. Currently existing biodiesel production is not used as a raw sunflower. If we consider an average of 30,234 ha of harvested area in sunflower period of 2000 . by 2010 . 13.000ha year and uncultivated land, with an average sunflower yield from $2.36 \mathrm{t} / \mathrm{ha}$ with oil content of $46.54 \%$ (Krizmanic et al., 2008), we arrive at a figure of 46,097 tonnes of biodiesel.

Current treatment plants have been able to produce that amount of biodiesel and crude oil processed. It should be noted that the calculation is made on the basis of $100 \%$ of the average annual production of sunflower in Croatia, and maximum use of uncultivated land. Imported quantities are not taken into account. Such a scenario is not realistic achievable but shows theoretical production possibilities of biodiesel from sunflower.

At the moment, operating three factories engaged in the production of biodiesel, which can be seen in Table 3 Biodiesel factory Vukovar and biotron Ozalj have production capacity 35,000 tons / year, or 20,000 t / year. Both factories based on their production of rape as the main raw material. Vitrex Virovitica factory has a production capacity of 6,000 $\mathrm{t} /$ year, and biodiesel produced from waste oil. In the phase of the planned construction of four factories: OGV Varazdin with a production capacity of 20,000 t / year, Bion Koprivnica with a production capacity of 100,000 t / year, INGRA Slavonski Brod with a production capacity of 150,000 t / year, KEPOL Zadar with a production capacity of $60,000 \mathrm{t}$.

\subsection{Viability of production}

The viability of biodiesel production is limited available agricultural land that can be diverted from food production to the production of raw materials for biodiesel. Pimentel (2001) shows that to produce a liter of vegetable oil to consume $65 \%$ more energy from fossil sources than the energy potential of sunflower oil. Some results suggest that removal of aboveground parts for the production of ethanol decreases the rate of accumulation of organic carbon in the soil. The authors point out that the use of biomass for the production of biofuels causes soil acidification and eutrophication of water. Driver of biofuel production in the EU, the U.S. and Canada is mainly political, including tax breaks, subsidies and mandatory blending of biofuels with fossil fuels. Increased demand for raw materials for the production of biofuels affects the increase in raw material prices and thus makes biofuels less competitive compared to fossil fuels.

\section{ADVANTAGES AND DISVANTAGES OF BIODIESEL}

There is a three main aspects of biodiesel advantages over a fossil fuels: ecological, energy and economics aspects. Ecological aspects:

- reduced emissions of greenhouse gases, 
- reduced particles: $\mathrm{CO} 2, \mathrm{CO}, \mathrm{SO} 2$, $\mathrm{NO} 2$,

- nontoxic.

Energy aspects:

- basic raw materials and the use of renewable energy,

- reduces the need to import oil.

Economic aspects:

- employment,

- expansion in industrial production,

- additionally funds to agriculture,

- contribution to the economic development.

Deficiencies are reflected in:

- insufficient quantity for the total replacement of diesel fuel estimated to be in optimal conditions biodiesel could meet 20 - $30 \%$ of total demand,

- due to intense suppuration farms where it is grown rape leads to the formation and evaporation of nitric suboxide which is resulting in the acid rain,

- Is hygroscopic, so the storage should take additional measures to protect against moisture.

- Relatively poor energy balance of biodiesel production (to produce one liter of biodiesel takes about half a liter of mineral diesel).

Results of using biodiesel in a conventional diesel engine is substantial reduction of unburned hydrocarbons, carbon monoxide and particulate matter. Emissions of nitrogen oxides are either slightly reduced or slightly increased depending on the cycle of the engine and testing methods used. Biodiesel has the advantage over fossil fuels in reducing emissions so that the mixture B20 reduces hydrocarbon emissions by $20 \%$, carbon monoxide and particulate matter by $12 \%$ and sulfur content of about $20 \%$.
NOx emissions are also growing at $2 \%$. Biodiesel is degraded $95 \%$ after 28 days, and diesel fuel is only $40 \%$ for the same period.

\section{RESULTS AND DISCUSSION}

In the period between 2007. and 2011. under consideration there is significant fluctuation in the number hectares of the surfaces planted with oil seed rape and an average yield. In 2008, oil seed rape was grown on 22,401 ha which are followed by a fall at 8.413 ha, and in the last two years the surfaces increase again to be 16,464 ha in 2010, and 17.838 ha in 2011. Results is in table 2.

Table 2. shows that the consumption of fossil fuels records a fall by $7.2 \%$ when the years 2007. and 2010. are compared. Following such a falling trend in consumption of fossil fuels as in 2010, Croatia should produce $35,236 \mathrm{t}$ of biodiesel in 2020. Given that the production of $1 \mathrm{t}$ of biodiesel requires some $3 \mathrm{t}$ of oil seed rape, then it can be concluded that Croatia should increase the surfaces under oil seed rape at 30.000 ha, namely, by $40.6 \%$ by 2020 . in order to meet the EU requirements. Otherwise, it should import oil seed rape.

\section{CONCLUSION}

Due to the world's limited crude oil reserves and increasingly higher emission of glass-house gases, the production and consumption of biodiesel, as an alternative fuel, has become an inseparable element of modern agricultural production. Significant impacts on economic, industrial, and strategic interests as well as a minimal negative impact on environment are the factors indicating the inevitability of introducing biodiesel into usage. Given that there are some 600.000 ha of fallow farm land in Croatia today, and with existence of aforementioned favourable climatic factors, it is obvious 
that Croatia has good prospects of increasing the production of biodiesel.

An important figure in the analysis of the production is to increase the production of biodiesel automatically leads to a reduction in surface area for food production, which will lead to increase in prices of food.

However, the production of biofuels is actually the direct transformation of food into oil so the extra demand for some types already raised prices and thus directly increase the prevalence of hunger in the world, because it means higher prices and less availability of food to poor countries In the incident with the production of biodiesel and environmental protection, as the most important aspects occurs food prices. Since the increase of production of biodiesel, directly reduce the surface for food. The question is what will be in in the future be designated as the primary of the worlds politics.
Croatia as a touristic country, during the spring and summer months visit up to 10 million tourists, and should turn to the production of biodiesel from waste cooking oil, and thus make a double benefit. First, not confiscated land to grow crops, and could also processed a considerable amount of waste oil, which in most cases end up in nature.

\section{REFERENCES}

1. Lulić, Z. (2010): Biodizel kao pogonsko gorivo

2. Statistical report 2011.

3. epp.eurostat.ec.europa.eu

4. http://faostat.fao.org

5. Pimentel, D. (2001): Biomass utilization

6. Krizmanić, M., Liović, I., Mijić, A., Bilandžić, M., Duvnjak, T. (2008): Nova generacija OS hibrida suncokreta tolerantnih na sušu i visoke temperature

7. Franić, D. (2010): Postrojenja za proizvodnju biogoriva

8. dzs.hr 